\title{
Research on Improving Collaborative Innovation Ability of Higher Education and Manufacturing Development
}

\author{
Wei-Na LIU ${ }^{1, a}$, Dong-Nan SU ${ }^{2, b}$, Chun-Mei LI ${ }^{3, d,{ }^{*}}$ and Zhi-Gang LIU ${ }^{4, c}$ \\ ${ }^{1}$ College Of Optical And Electronical Information Changchun University of Science and Technologe, \\ Mechanical And Electrical Engineering ,Changchun City, Jilin Province, China . \\ ${ }^{2}$ College Of Optical And Electronical Information Changchun University of Science and Technologe, \\ Mechanical And Electrical Engineering ,Changchun City, Jilin Province, China. \\ ${ }^{3}$ College Of Optical And Electronical Information Changchun University of Science and Technologe, \\ Mechanical And Electrical Engineering ,Changchun City, Jilin \\ ${ }^{4}$ College Of Optical And Electronical Information Changchun University of Science and Technologe, \\ Mechanical And Electrical Engineering ,Changchun City, Jilin

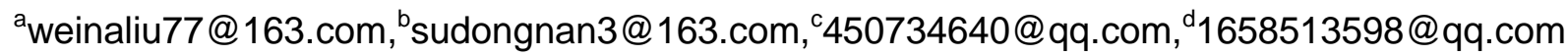 \\ * Chun-Mei LI
}

Keywords: Higher education, Manufacturing, Collaborative innovation ability

\begin{abstract}
This article starts from two aspects of higher education and manufacturing, Put forward the problems in the co-innovation of higher education and manufacturing development, combined with the actual situation of the school , make clear the five aspects of collaborative innovation ability of higher education and manufacturing development, It is concluded that the system has an important effect on the realization of its function, it is the fundamental guarantee for the implementation of innovation mechanism reform.
\end{abstract}

\section{Introduction}

The basic function of higher education is to train specialized personnel, scientific research and serving society. Since the Reform and Opening, China's higher education has made great strides, has made remarkable achievements, the socialist higher education system with various levels, forms and disciplines basically completed to meet the needs of national economic construction and social development has been initially formed. In the socialist modernization construction, training a large number of advanced specialized talents, national economic construction, scientific and technological progress and social development, it has played an important role.

Manufacturing is the pillar industry of the national economy, and it is also an important manifestation of the overall national strength. China's manufacturing industry has been developing rapidly, China has become the world's largest manufacturing country and is moving towards manufacturing power. Innovation and development of manufacturing industry can not be achieved without collaborative innovation among multiple subjects such as universities, enterprises, research institutes, governments, financial institutions and associations. From a systematic perspective, collaborative innovation is a systematic project, a variety of innovative subjects constitute a subsystem of collaborative innovation system, the external environment together constitute a complex ecosystem.

Regard colleges and universities, enterprises, research institutions as the core elements, regard network Innovation with Synergistic Interaction among Government, Financial Institutions, Intermediary Organizations, Associations, Non-Profit Organizations as auxiliary elements. It aims to deepen cooperation and resource integration through knowledge creation subject and technical innovation subject. Maximize the functions of all the elements and open a new era for the synergistic development of higher education and manufacturing.

However, the following problems still exist in the co-innovation of higher education and manufacturing: First, The target of each innovation subject is not the same, the value orientation is 
different; Second, in the collaborative innovation system, organization and management, division of labor orientation, coordination of interests and other mechanisms are not perfect. The initiative and innovation potential of each innovative subject has not been fully utilized, making the overall function of collaborative innovation system failed to be played; Third, the exchange and interaction between the various innovation bodies is not sufficient, innovative resource allocation efficiency is not high, which do not form a joint force; Fourth, the external social environment and social atmosphere of the collaborative innovation system need to be further nurtured. Only by solving these problems can we effectively improve the co-innovation ability of higher education and manufacturing. To do this, we need to clarify the following issues

\section{First. The Correlation between the Target and Value Orientation of Each Innovation}

Higher education is one of the main innovation bodies, its goal is to train specialized personnel that suits the needs of modern science, technology and society. The value orientation of higher education is to cultivate and promote students with the constant pursuit of truth and wisdom ,knowledge and ability which achieve the sustainable development and paying attention to individual differences in personnel. In the social environment, trained personnel will be better able to play their talents and make corresponding contributions.

The training goal of higher education needs to be constantly updated as the background of the times changes. Therefore, the goal of higher education should be constantly updated. Teaching should need reform, which needs to achieve a comprehensive course between specialized course and elective courses. Now the manufacturing needs specialized personnel, which is the reality that higher education must face. At present, education is far from reality, we should find a meeting point between them. Nowadays, colleges and universities are also aware of the seriousness of the problems. While making the students' knowledge structure more reasonable, they pay more attention to cultivate their abilities in vocational skills, analysising and solving problem. So that students can be fully developed, school can achieve a comprehensive academic education. Innovative talent training is limited, because the curriculum structure is not justified and knowledge teaching method and teaching concept lag behind. Which is preventing science and engineering students from gaining broader knowledge of modern manufacturing, and restricting the cultivation of students' creative ability.

According to manufacturing demand for talent is multi-level, multi-faceted. Not a university can accomplish all kinds of talents training tasks at all levels. Different levels of higher education need to proceed from reality, Which determine the direction and level of personnel training needs, Which establish a complete and reasonable education system and evaluation criteria. Provide personalized services for enterprise needs. Therefore, the current problem of higher education needs to be solved is that with the continuous improvement of the times and the rapid development of science and technology, the teaching system and mode should reform. Collaborative innovation with manufacturing, Promoting innovative talent cultivation to promote the development of manufacturing industry.

Manufacturing as another innovative subject, entrepreneurial innovation, profitability, creating economic benefits and realizing real economic growth are the goals and main values of manufacturing industry. The realization of these goals, on the one hand, depends on the quality of the enterprise itself. On the other hand, enterprises want to innovate, realize manufacturing modernization and implement "made in China 2025", which needs applied creative talents, engineers with intelligent manufacturing, entrepreneurs with mind of industrial 4.0 , science and technology leader with the Internet mind and is proficient in manufacturing engineering. Enterprises need to actively promote the integration of innovative resources such as talent, technology, capital, information and services globally, and use these resources effectively, to find and cultivate new growth drivers. At home and abroad to carry out a wide range of deep-level cooperation in personnel, technology, capital, information, services. Create a chain of innovation based on the manufacturing chain, promote the transformation and upgrading of manufacturing industry and enhance the capability of collaborative innovation. 
Institutions of higher learning, enterprises, research institutions, government, financial institutions, intermediary organizations, associations, non-profit organizations and other kinds of innovation main body, all belong to different nature of the organization, is engaged in the different social division of labor, and exists heterogeneity. Heterogeneous production capacity determines their different functions in the regional economic and social system. All parties have different work objectives and values. But in the collaborative innovation system, the community is formed. All parties have needs, for example, personnel training, personnel use, project sources, project development, financial orientation, the results of applications, serving the community and more. Collaborative innovation system enables the flow of heterogeneous innovation bodies such as schools, enterprises, research institutions, governments, financial institutions, intermediary organizations, associations, and non-profit organizations. For example, higher science and engineering universities and enterprises have their own advantages in technical innovation. Utilizing the advantages of intellectual support and talent in colleges and universities, for technical problems in manufacturing industry, Talents cultivation and technological research and development in institutions of higher education provide innovative services to the manufacturing industry, Which has gradually become an important model for higher education and enterprises to jointly promote technological innovation in manufacturing industry. It is precisely because of the internal laws of cooperation between heterogeneous innovation entities, Which has the impetus for collaborative innovation. To form a cooperative and innovative mechanism for sustainable development. Therefore, the synergetic innovation among the various innovation entities is the frontier innovation mode of knowledge and technology innovation in the future.

\section{Second. Improve the Organizational Management, Division of Labor and Interests Coordination Mechanism of Collaborative Innovation System, Optimize the Overall Function of Collaborative Innovation System.}

The work mode of collaborative innovation system is the comprehensive cooperation of each subject innovation system. Establish a scientific discipline assessment standards. Guide innovation and engineering ability training. Enterprises should become the main body of investment R \& D, application achievement and integrated innovation. It should play a role in providing technical information such as technical requirements, technical resources, venues, capital, and customer-oriented services. In the area of finance and technology and industrial cooperation, the capital environment of manufacturing should be improved. Should guide more money to the real economy and advanced manufacturing industries, strengthen financial support for innovation. Which is the key to the successful implementation of "made in China 2025". The function of government is to conduct top-level design and scientific and effective regulation. Which formulates policies and mechanisms for the coordination of interests between various innovative subjects and bring together limited social resources, bring together limited social resources and strengthen collaborative innovation. Improve the innovation policy, promote cooperation between industry, universities and research institutes. optimize the overall function of collaborative innovation system. In clarifying government requirements, collaborative innovation process, within the framework of co-innovation set up by the government, play their respective strengths in talent cultivation and technological innovation, coordinate the relationship, promote collaborative innovation between universities and manufacturing industries.

\section{Third. Optimize the Allocation of Innovative Resources and Enhance the Exchange and Interaction Among Various Innovation Entities.}

Establishing an Integrated Mechanism of Collaborative Resources among Innovative Subjects. The innovation resources including human resources, hardware and equipment resources, software resources (technical standards, patents, etc.) and the intellectual resources, knowledge and technological innovation of vocational colleges are optimized and integrated under the overall framework of collaborative innovation. Constantly meet the resource needs. Constantly meet 
technical skills accumulation, skill training and the resource demands of technological innovation. Accelerate the construction of a national, provincial manufacturing collaborative innovation center and a collaborative innovation service plat. Collaborative innovation service platform can enhance the connection and connection between various links in the technological innovation chain. The collaborative innovation center of manufacturing industry is composed of various innovative resources, such as high school, enterprise, scientific research institute, industrial fund, social capital, etc. Through the establishment of collaborative innovation service platform, make each innovation main body into the collaborative innovation system, innovation system, improve the technological innovation mode, optimize the allocation of resources, strengthen the exchange of information and interaction among various innovation entities, form synergy and improve the technical innovation ability of the whole nation. Launch on the collaborative innovation center platform, aggregate social innovation resources, breakthrough information "island". Strengthen technical cooperation, give play to their respective advantages, share knowledge. Collective research, promote major, common, basic, applied and other types of project research. Make full use of manufacturing resources. Effectively solve the problems of technology, capital and industrialization that manufacturing industry faces. Promote the formation of China's manufacturing industry to participate in the new international competition advantage.

\section{Forth. Foster Collaborative Innovation System of External Social Environment and Social Atmosphere.}

Collaborative innovation system has an open character. From the external environment, the structure and function of the system are constantly adjusted by political, economic and cultural influences. Countries actively promote collaborative innovation is open to all types of colleges and universities. Extensively absorb research institutes, industrial enterprises, local governments and international innovation forces. Form an open organization operation mode. The development and implementation of collaborative innovation should be oriented by demand. That is to adapt to the needs of national development, regional economic development and the development of enterprises in the industry

Strive to create a social environment that encourages innovation. In addition to the need for technology, talent and financial support for innovation and development, there is also a need to create a social environment and atmosphere that encourages innovation. Create a culture of cooperation and win-win situation, improve relevant laws, rules and regulations, maintain a fair and equitable market environment and respect the legal environment of intellectual property; Vigorously cultivate the spirit of craftsmen and entrepreneurship, create a social atmosphere that supports innovation and tolerates failure, and fully stimulate the initiative and creativity of all innovation entities. Which provides a strong and lasting impetus to the economic development of our country.

\section{Fifth. Machine Design Manufacture and Automation Speciality and Machine-Building Industry Collaborative Innovation Exploration.}

College Of Optical And Electronical Information Changchun University of Science and Technologe, Mechanical And Electrical Engineering, Machine design manufacture and automation speciality is a specialty in Jilin Province. Over the years, which has been engaged in the teaching reform of education, continuing professional construction, and sticking to the path of university-enterprise cooperation and collaborative innovation. Joint more than 20 machinery manufacturing enterprises in the province. Set up a number of co-innovation between production and teaching platform. In terms of talent cultivation, scientific research, achievement transformation and service society, the actual results have been achieved: One is that all kinds of practice activities in the field are arranged in the manufacturing enterprises. Combining with the actual project of the enterprise, the topic of graduation design is selected and completed. Implement the excellent engineer program. Junior third semester professional courses arranged in the business lecture. Research and development, 
design and manufacture mechanical products in the internship. Participated in the design of changchun kaidi automobile body design co., LTD. Design of the new express sedan door and interior accessories, all manufactured products and used in practice. Established a cooperation agreement with changchun optical precision machinery and physics research institute. Set up a school of scientific research, high-level personnel training, internship practice platform. Cooperation between school and enterprise Conducts scientific research and improves teachers' research ability. Allow the main body to maximize the enthusiasm and initiative

In a word, collaborative innovation system in which colleges and universities, industry enterprises, research institutions, financial institutions and intermediaries and other subjects to participate. It is the most important premise to ensure the function of the system to allow the main body to maximize the enthusiasm and initiative. Establish a relevant system of innovation management, politics, economy, personnel management and assessment and evaluation. The system in collaborative innovation system plays an important role in the realization of its function, which is the fundamental guarantee for the reform and implementation of the innovation mechanism system

\section{References}

[1] HE Jun, HUANG Yang-hua, SHEN Yun-chang. Optimal Institutional Arrangements for School-Enterprise Cooperation and R \& D [J] .China Industrial Economics, 2011, (2): 151-160.

[2] The Game Theory Interpretation of Wesson-Hayek's Spontaneousity Theory [J] .Chinese Social Sciences, 2003, (6): 43-57.

[3] Zhang Xuewen. Collaborative innovation of production, study and research under the perspective of open science [J]. Science of Science, 2013, (4): 617-622.

Tu Zhenzhou, Gu Xin.Study on collaborative innovation process of production, study and research based on knowledge flow [J]. Science of Science, 2013, (9): 1381-1389.

[5] Fan Ruguo. Collaborative Innovation of Social Governance under the Paradigm of Complex Networks [J] .Chinese Social Sciences, 2014, (4): 98-120.

[6] Xu Guoshi. System Science [M]. Shanghai: Shanghai Science and Technology Education Press, 2000.29.

[7] Li Jianqiu, Qing Zhongquan.Corporate Innovation and Development of Higher Vocational Education [J] .Journal of Higher Engineering Education, 2013 (, 5): 118-122.

[8] He Yu ice. Theory of collaborative innovation of production, study and research [J]. Science of Science, 2012,30 (2): $155 \sim 174$.

[9] Yan Xiong. The five major issues of collaborative innovation of industry, university and research urgently need to be solved [N]. China Hi - tech Industry Herald, 2007-03-19.

[10] Tang Yang. Reflections on collaborative innovation in colleges and universities [J]. Chinese University Technology 2012 (7).

[11] Gong Ke. Large scientific era requires large collaborative innovation [N]. China Education Daily, 2012-06-11 (5).

[12] Ning Bin. Colleges and universities in the collaborative innovation in the status and role of N]. People's Daily, 2012-04-19 (7).

[13] Yin Xiangwen. The Role and Value Pursuit of Collaborative Innovation in Colleges and Universities [J]. Chinese University Technology, 2012 (7).

[14] Jianli Rong. Internationally typical collaborative innovation mechanism of research [J]. University Education Management, 2012,6 (5). 
[15] Liu Haifan. Modern leadership encyclopedia · law and philosophy volume [M]. Beijing: CPC Central Party School Press, 2008. 